\title{
Local angiotensin II contributes to tumor resistance to checkpoint immunotherapy
}

\footnotetext{
* Correspondence: xieguozhu@126.com; yuanyawei2015@outlook.com ${ }^{\dagger}$ Guozhu Xie, Tan Cheng and Jie Lin contributed equally to this work. 'Department of Radiation Oncology, Nanfang Hospital, Southern Medical University/The First School of Clinical Medicine, Southern Medical University, Guangzhou 510515, Guangdong, China

Full list of author information is available at the end of the article of its effector functions are, however, mediated by AT1R [8]. In addition to this systemic RAS, AngII can also be produced in alternative pathways in local tissues across diverse organ systems including the kidney, heart,

(c) The Author(s). 2018 Open Access This article is distributed under the terms of the Creative Commons Attribution 4.0 International License (http://creativecommons.org/licenses/by/4.0/), which permits unrestricted use, distribution, and

important factor allowing for tumor cell immune escape in vivo is the intratumor immunosuppressive microenvironment [6].

The renin-angiotensin system (RAS) is classically known as a circulating or hormonal system that regulates blood pressure, electrolytes, and fluid homeostasis [7]. The classical RAS consists of several components: hepatic-derived precursor angiotensinogen (AGT), renally synthesized renin, pulmonary-bound angiotensin-converting enzyme (ACE), and the physiologically active peptide angiotensin II (AngII). AngII is a key bioactive RAS peptide which elicits its effects by binding to its receptors, AngII type 1 receptor (AT1R) and AngII type 2 receptor (AT2R); most 
vasculature, pancreas, and adipose tissue [9]. AngII overproduction plays an important role in the development of chronic diseases, including atherosclerosis [10], diabetic nephropathy [11], and retinopathy [12].

Interestingly, a retrospective study provided evidence that patients with hypertension taking ACE inhibitors and AngII type 1 receptor blockers (ARBs) had a decreased risk of developing some types of cancers [13]. Recent clinical trials showed the candesartan, one of the ARBs, prolonged patients' survival and improved clinical outcomes in patients with advanced pancreatic cancer $[14,15]$. Sub-clinical studies from animal xenograft models and human malignancies observed the frequent dysregulation of RAS components in the tumor microenvironment and a correlation with disease outcomes [7], indicating an important role for local RAS in modulating tumor biology. Our group has previously reported [16] that in human breast cancer and nasopharyngeal carcinoma, the local AngII predominantly exists in the hypoxic regions of the tumors. We demonstrated that tumor cells in hypoxic microenvironments produced AngII by a hypoxia-lactate-chymase-dependent mechanism, which is different from the classical AGT-renin-ACE-AngII pathway [7].

Other previous studies showed that AngII induced a variety of chronic organ diseases via the infiltration and activation of fibroblasts $[17,18]$ and macrophages $[19,20]$. It is notable that fibroblasts and macrophages are important stromal cells and their activation within the tumor microenvironment, in which they become cancer-associated fibroblasts (CAFs) and tumor-associated macrophages (TAMs), contributes to the formation of an intratumoral immunosuppressive microenvironment [6].

In general, macrophages can be polarized to $\mathrm{M} 1$ or $\mathrm{M} 2$ phenotype [21]. M1-polarized macrophages, also known as classically activated macrophages, produce pro-inflam matory and immunostimulatory responses to infection. TAMs are thought to more closely resemble M2-polarized macrophages [22], which are activated by Th2 cytokines (e.g., IL-4, IL-10, and IL-13). TAMs are the major immunoregulatory cells and result in the immune suppression in the tumor microenvironment [23]. In breast tumors, macrophages is the most prevalent immune cells, exerting a profound influence over the immunologic state of neoplastic tissues [24]. Recruitment of monocytes and cultivation of TAMs in the tumor microenvironment are now recognized as key features of breast cancer progression [24]. Additionally, recent studies provide strong evidence that TAMs facilitate colorectal cancer growth by altering extracellular matrix remodeling, tumor metabolism, angiogenesis, as well as the tumor microenvironment [25].

Since local AngII is present in the tumor microenvironment [16], there is a possibility that it may mediate the recruitment and activation of fibroblasts and macrophages in the tumor microenvironment to participate in the formation of this immunosuppressive microenvironment.

The 4T1 breast cancer and CT26 colon cancer cells are the most popular syngeneic mouse tumor models, particularly for cancer immune research. More importantly, these two tumor models exhibit different sensitivity to immune checkpoint blocker, in which $4 \mathrm{~T} 1$ breast tumors are resistant to checkpoint immunotherapy and CT26 colon tumors show modest sensitivity to checkpoint immunotherapy [26, 27]. Here using these two tumor models, we demonstrate that local AngII plays an important role in the formation of a tumor immunosuppressive microenvironment. Blockage of AngII effector functions greatly improves tumor sensitivity to checkpoint immunotherapy.

\section{Methods \\ Reagents}

The following antibodies were used for the animal experiments: mCD152 (mCTLA-4) monoclonal antibody (9H10; Bio X Cell), mPD-1 monoclonal antibody (RMP1-14; Bio X Cell), anti-mouse CD8 monoclonal antibody (116-13.1, Bio X Cell), polyclonal Syrian hamster IgG (Isotype Controls of anti-mouse CTLA-4, Bio X Cell ), rat IgG2a isotype control (Isotype Controls of anti-mouse PD-1, Bio X Cell ), and mouse IgG2a isotype control (Isotype Controls of anti-mouse CD8, Bio X Cell).

\section{Cell lines and culture}

4T1 (murine breast cancer cells) and CT26 (murine colorectal adenocarcinoma) were purchased from American Type Culture Collection (ATCC). Both tumor cell lines were grown in RPMI-1640 medium supplemented with $10 \%$ fetal bovine serum at $37^{\circ} \mathrm{C}, 5 \% \mathrm{CO}_{2}$. For hypoxic culture, cells were cultured in a hypoxia chamber $\left(37^{\circ} \mathrm{C}\right.$ with an atmosphere of $1 \% \mathrm{O}_{2}$ and $5 \%$ $\mathrm{CO}_{2}$, balanced with $\mathrm{N}_{2}$, and humidified). For normoxic culture, cells were cultured in an atmosphere containing $21 \% \mathrm{O}_{2}\left(37^{\circ} \mathrm{C}\right.$ and an atmosphere of $5 \% \mathrm{CO}_{2}$ equilibrated with atmospheric $\mathrm{O}_{2}$ in a humidified incubator).

\section{Construction of shRNA lentiviral vector and establishment of AGT-silenced cells}

The designed shRNA construct, as previous studies [16], contained a unique 19-nt double-stranded AGT target sequence that presented as an inverted complementary repeat, a loop sequence (5'-CTCGAG-3'), the RNA PloIII terminator (5'-TTTTTT-3'), and 5' single-stranded overhangs for ligation into AgeI- and EcoRI-digested Pglv-u6-Puro lentivirus vector (GenePharma, Shanghai, China). The recombinant vector was named pGLVAGT-shRNA. The negative control vector (pGLV-NCshRNA) contained a nonsense shRNA insert in order to control any effects caused by non-RNAi mechanisms. 
We co-transfected the $293 \mathrm{~T}$ cells with three optimized packaging plasmids (pGag/Poll, pRev and pVSV-G) and the pGLV-AGT-shRNA or Pglv-NC-shRNA expression clone construct, which produced lentiviral stocks with a suitable titer. Stably transduced 4T1 and CT26 cells were selected using puromycin, adding the minimum concentration of puromycin required to kill untransduced 4T1 or CT26 cells. The efficiency of knockdown was detected by real-time qPCR and western blotting.

\section{Quantitative RT-PCR}

Total RNA was extracted from cells using TRIzol reagent (Invitrogen) according to the manufacturer's protocol. Then, reverse transcription was performed with the PrimeScript ${ }^{\oplus}$ RT reagent kit (Takara), followed by real-time PCR using an ABI 7500 Sequence Detection System with a SYBR ${ }^{\circ}$ Premix Ex Taq $^{\text {Tix }}$ kit (Takara). The sequences of the specific PCR primers were as follows:

AGT: Forward: 5'-TGAAGGATACACAGAAGCA A-3'

Reverse: 5' -TGGTAAAGGAGATGGAAGG-3'

GAPDH: Forward: 5' - TGTCGTGGAGTCTACTGGT G-3'

Reverse: 5' -GCATTGCTGACAATCTTGAG-3'

GAPDH was used as the internal control.

\section{Western blotting}

Whole cell lysates were harvested and Western blotting was conducted as described previously [16]. Primary antibodies are listed in Table 1. Blots were visualized using an ECL detection kit (Millipore). Antibodies for Western blotting were listed in Additional file 1 : Table S1.

\section{Detection of cell proliferation ability}

Cell proliferation ability was detected by MTT assays. Cells were plated into 96 -well plates $\left(2 \times 10^{3}\right.$ cells/well $)$ in $200 \mu \mathrm{L}$ of medium. After incubation for $8 \mathrm{~h}$, cells were exposed to candesartan $(10 \mu \mathrm{m} /$ well, a selective AT1R blocker), PD123319 (10 $\mu \mathrm{m} /$ well, a selective AT2R blocker), a combination of these $(10 \mu \mathrm{m} /$ well candesartan and $10 \mu \mathrm{m} /$ well PD123319), and control DMSO for $0,24,48,72$, and $96 \mathrm{~h}$. At each time point, $20 \mu \mathrm{L}$ of $5 \mathrm{mg} / \mathrm{mL}$ MTT solution in PBS was added to each well for $4 \mathrm{~h}$ at $37{ }^{\circ} \mathrm{C}$. Subsequently, a $20 \%$ sodium dodecyl sulfate (SDS) solution in $0.01 \%$ $\mathrm{HCl}(150 \mu \mathrm{L})$ was added to each well, and the absorbance at $570 \mathrm{~nm}$ was measured using a spectrophotometric plate reader (ND-1000, Wilmington, DE). Two independent experiments were performed, each in triplicate.

Table 1 Cytokines influenced (alteration>2folds) by AGT silence

\begin{tabular}{|c|c|}
\hline Cytokines & Functions \\
\hline \multicolumn{2}{|l|}{ Immune-activating } \\
\hline IL-7 & Necessary for both B-cell and T-cell proliferation [43]. \\
\hline IL-20 & Enhancing innate and adaptive immunity [44]. \\
\hline CD40 ligand & A potent dendritic cell activation molecule, counteracting immune escape mechanisms in the tumor microenvironment [45, 46]. \\
\hline CXCL1 & Pro-inflammatory cytokine: the activation and regulation of innate and adaptive immunity [53]. \\
\hline CXCL11 & Chemotactic for activated T cells [47]. \\
\hline CXCL14 & Attraction of dendritic cells [48] \\
\hline TNFSF14 & Stimulating lymphocyte proliferation and tumor cell-specific anti-tumor immune responses [49]. \\
\hline \multicolumn{2}{|l|}{ Immunosuppressive } \\
\hline IL-3 & Promoting dendritic cells secreting significantly less IL-12 p70 and more IL-10 [54] \\
\hline IL-4 & Participating in both TAM and MDSC survival and the acquisition of an immune-suppressive phenotype [55, 56]. \\
\hline $\mathrm{IL}-10$ & Inhibiting the ability of APCs to present antigens to T cells [57] \\
\hline Fas & Inducing apoptosis of cytotoxic T Iymphocytes through the FAS-FASL pathway [58] \\
\hline Fas ligand (FASL) & Inducing apoptosis of cytotoxic T lymphocytes through the FAS-FASL pathway [58] \\
\hline CCL1 & Specific recruitment of regulatory T cells in ovarian carcinoma fosters immune privilege [59] \\
\hline CCL7 & Chemoattracting MDSCs and Tregs in tumor microenvironment [60]. \\
\hline SDF-1 & Increasing immunological tolerance by polarizing Tregs [61]. \\
\hline $\mathrm{CCL} 28$ & Recruiting Tregs in tumor hypoxia microenvironment [62]. \\
\hline G-CSF & Recruiting MDSCs in tumor hypoxia microenvironment [63]. \\
\hline GM-CSF & Shaping the tumour microenvironment by promoting myelopoiesis and recruitment of suppressive myeloid cells [55, 64, 65] \\
\hline Eotaxin-2 & the recruitment and polarization of Tregs $[66,67]$. \\
\hline TNFSF12 & Curtailing the innate response and its transition to adaptive TH1 Immunity [68]. \\
\hline
\end{tabular}




\section{Sirius Red staining}

Sirius Red staining was performed as previously described [28]. Formalin-fixed tissues were embedded in paraffin and sectioned at $5 \mu \mathrm{m}$ thickness.Sirius Red staining for collagen was performed using $0.1 \%$ Sirius Red (Direct Red80; Sigma) and counterstained with Weigert's hematoxylin.

\section{Flow cytometry}

The following anti-mouse antibodies were used for flow cytometry: Live/Dead Fixable Near IR Dead Cell Stain (Life Technologies), CD45-PerCP-Cy5.5 (BD Biosciences), CD3-PE (BD Biosciences), CD44-PE (BD Biosciences), CD8a-APC (BD Biosciences), CD4-APC (BD Biosciences), Foxp3-PE (BD Biosciences), CD11b-PE-Cy7 (BD Biosciences), F4/80-APC (BD Biosciences), Ly6C-PE (BD Biosciences), Ly6G-FITC (BD Biosciences), and Ly6G-APC-Cy7 (BD Biosciences). Flow cytometry was performed with Canto II (BD) and the data were analyzed with FlowJo 7.6 software (TreeStar). Live/dead cell discrimination was performed using Live/Dead Fixable Aqua Dead Cell Stain Kit (Life Technologies). All of cell surface or intracellular stainings were done according to the manufacturer's instructions. $\mathrm{T}$ effector cells $\left(\mathrm{T}_{\text {eff }}\right)$ were phenotyped as $\mathrm{CD} 45^{+} \mathrm{CD} 8^{+} \mathrm{CD} 44^{+}$, regulatory $\mathrm{T}$ cells $\left(\mathrm{T}_{\text {regs }}\right)$ as $\mathrm{CD}_{4} 5^{+} \mathrm{CD} 4^{+} \mathrm{Foxp}^{+}$, macrophages as $\mathrm{CD} 45^{+} \mathrm{CD} 11 \mathrm{~b}^{+} \mathrm{F} 4 /$ $80^{+}$, tumor-associated macrophages (TAMs) as

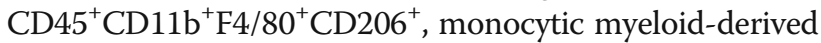
suppressor cells (Mo-MDSCs) as $\mathrm{CD} 45^{+} \mathrm{CD} 11 \mathrm{~b}^{+} \mathrm{Ly}_{6 \mathrm{G}} \mathrm{G}^{\text {low- }}$ Ly6 $\mathrm{C}^{\text {high }}$, and granulocytic myeloid-derived suppressor cells (G-MDSCs) as CD $45^{+}$CD $11 b^{+} \mathrm{Ly}_{6 G^{\text {high }}} \mathrm{Ly}_{6 C^{\text {low }}}$.

\section{ELISA}

AngII, IL-10, GM-CSF, G-CSF, Eotaxin-2, and CXCL11 ELISA kits were all obtained from Ray Biotech, Inc. (Norcross, GA, USA). TNFSF14 ELISA kits was obtained from CUSABIO Inc. (Wuhan, China). The ELISA for them was carried out according to the manufacturer's instructions. Two independent experiments were performed, each in triplicate. For AngII ELISA, the microplate in the kit, which is pre-coated with anti-rabbit secondary antibody, was incubated with an anti-AngII antibody, under such conditions that both biotinylated AngII peptide and a peptide standard or targeted peptide in the samples interacted competitively with the AngII antibody. Unbound biotinylated AngII peptide was then allowed to interact with streptavidin-horseradish peroxidase (SA-HRP), which catalyzes a color development reaction. The intensity of the colorimetric signal is directly proportional to the amount of the biotinylated peptide-SA-HRP complex and inversely proportional to the amount of the AngII peptide in the standard or samples. A standard curve of known concentration of AngII peptide was established, and the concentration of AngII peptide in the samples was then calculated by interpolation onto the standard curve. All groups of tumor cells were all seeded at a density of 200,000 cells/ well in $1 \mathrm{ml}$ medium in 24-well plates.

\section{Immunofluorescence}

Initially, 5- $\mu \mathrm{m}$ frozen tissue serial sections were fixed with cold acetone for 15 minutes at $4^{\circ} \mathrm{C}$ and then washed three times for five minutes each with phosphate-buffered saline. Slides were blocked for one hour in $5 \%$ bovine serum albumin at room temperature. Primary antibodies were incubated overnight at $4^{\circ} \mathrm{C}$. Following additional washes, the slides were incubated for one hour at room temperature with the appropriate secondary antibody and 4,6-diamidino-2-phenylindole (DAPI) counterstaining. To reduce autofluorescence, the slides were subsequently incubated in $0.3 \mathrm{M}$ glycine for 10 minutes and then mounted in Hydromount aqueous mounting medium (Fisher Scientific). Images were acquired with a fluorescence microscope (Olympus BX51). Antibodies used for the immunofluorescence are listed in Additional file 1: Table S1.

\section{Mouse cytokine antibody array analysis}

Cytokine profiles (containing 308 cytokines) of 4T1 cells in normoxic or hypoxic conditions were analyzed using the RayBio Mouse Cytokine Antibody Array. Protein extraction: total protein was extracted from the cells with ice-cold Cell \& Tissue Protein Extraction Reagent (KangChen. Cat. \# KC-415, China), which contains inhibitors for protein degradation (5ul Protease Inhibitor Cocktail, $5 \mu \mathrm{l}$ PMSF and $5 \mu \mathrm{l}$ Phosphotase Cocktail were added into the $1 \mathrm{ml}$ Protein Extraction Reagent). Determining the protein concentration: the protein concentration was determined by using a BCA Protein Assay Kit (KangChen KC-430, China). Blocking and incubation: a. Protein array membranes were blocked in blocking buffer for $30 \mathrm{~min}$ and then incubated with samples at room temperature for 1 to $2 \mathrm{~h}$ (or incubated at $40{ }^{\circ} \mathrm{C}$ overnight). b. Samples were then decanted, and the membranes were washed with washing buffer. After that, the membranes were incubated with diluted biotin-conjugated antibodies at room temperature for 1-2 h. Chemiluminescent detection: the membranes were washed with washing buffer and then reacted with HRP-conjugated streptavidin (1:1000 dilution) at room temperature for $2 \mathrm{~h}$. The membranes were then washed thoroughly and exposed to detection buffer in the dark before being exposed to X-ray film. Afterwards, the membranes were exposed to X-ray film and the image was developed using a film scanner. Data analysis: by comparing the signal intensities, relative expression levels of cytokines were obtained. The intensities of the signals were quantified by 
densitometry. Positive controls were used to normalize the results from different membranes being compared. Fold changes in protein expression were calculated.

\section{Animal Models}

All experimental procedures were approved and overseen by Southern Medical University Institutional Animal Care and Use Committee, and were performed in accordance with the guidelines and regulations for animal experiments set down by Southern Medical University. Four-week-old female BALB/c mice, BALB/c nude mice and NOD/SCID mice were used for the different animal experiments. 4T1 cells $\left(5 \times 10^{6}\right.$ cells $)$ with or without AGT silencing via AGT shRNA lentiviral transduction were inoculated into the mammary fat pads of each mouse. CT26 cells $\left(5 \times 10^{6}\right.$ cells $)$ with or without AGT silencing were inoculated s.c. into the flank of each mouse. When the tumors were allowed to grow for the indicated time, different drugs or control agents were administered by intraperitoneal injection. Antibodies used for the in vivo immune checkpoint blockade experiments were given intraperitoneally at a dose of $250 \mu \mathrm{g} /$ mouse every three days (four times total) and included: anti-CTLA4 (9H10), anti-PD-1 (RMP1-14), polyclonal Syrian hamster IgG, and rat IgG2a isotype control. Mice CD8-depletion in vivo was performed according to a previous study [29]. In brief, anti-CD8 antibody or an IgG2a isotype control at a dose of $200 \mu \mathrm{g} /$ mouse was given 2 days prior to tumor implantations (day -2), day 0 , and then every 4 days for the duration of the experiment. To explore the influence of Ang II blockers on tumor growth in vivo, candesartan $(5 \mathrm{mg} / \mathrm{kg}$, i.p., Takeda Pharmaceutical Company Limited, Japan) and PD123319 (5mg/kg, i.p., Selleck Chemicals) were given every other day starting from day 5 after cell injection. Perpendicular tumor diameters were measured using calipers. Tumor volume was calculated using the formula $\mathrm{L} \times \mathrm{W}^{2} \times 0.5$, where $\mathrm{L}$ is the longest diameter and $\mathrm{W}$ is the shortest diameter.

\section{Statistics}

Statistical analyses of AngII, GM-CSF and G-CSF levels by ELISA assay, the percentages of Teffs, Tregs, TAMs and MDSCs by Flow cytometry and Teffs / Tregs ratio were performed by using Student's t test with SPSS 13.0 software. Two-way cell growth in vitro and tumor growth in vivo were evaluated using SPSS 13.0 software with two-way repeated-measures ANOVA. Analyses of survival patterns in tumor-bearing mice were performed using the Kaplan-Meier method, and statistical differences were evaluated according to the Mantel-Cox log-rank test. A $p$ value $<0.05$ was considered statistically significant.

\section{Results}

Local Angll in tumor microenvironments is involved in immune escape of tumor cells

We first established syngeneic tumor models with 4T1 breast cancer cells in immune-competent BALB/c mice. To test the effect of AngII signaling on the 4T1 tumors, $\mathrm{BALB} / \mathrm{c}$ mice bearing 4T1 tumors of moderate sizes were repeatedly treated with the AngII-receptor blockers candesartan for AT1R and PD123319 for AT2R. Although 4T1 tumor growth was slightly retarded by PD123319, significant inhibition of tumor growth was only observed when mice were treated by candesartan alone or a combination of them (Fig. 1a). To determine whether the anti-tumor growth effect of AngII signaling blockage was caused by directly inhibiting the proliferation of the 4T1tumor cells, the effect of AngII signaling blockage on 4T1 cell proliferation was evaluated in vitro by a MTT assay. We observed no difference in cell proliferative ability in vitro between the cells treated with candesartan, PD123319, combination of both, and DMSO (Fig. 1b). Furthermore, we performed the same in vivo experiment using $\mathrm{BALB} / \mathrm{c}$ nude mice that were T-cell immunodeficient. Neither candesartan nor PD123319 could inhibit tumor growth in these T-cell immunodeficient mice (Fig. 1c). These results indicate that AngII signaling may be involved in the immune escape of 4T1 tumor cells in BALB/c mice.

Next, to demonstrate the role of local AngII in mediating the immune escape of tumor cells in BALB/c mice, the expression of AGT, a precursor of AngII, was stably silenced in 4T1 breast cells and CT26 colon cancer cells by lentiviral vector-mediated short hairpin RNA (shRNA), and the efficacy of the knockdown was shown in Additional file 1: Figure S1. We examined AngII expression in hypoxic and normoxic conditions in 4T1 and CT26 cells with or without expression of AGT shRNA. Consistent with our previous report [16], hypoxia remarkably induced AngII generation in 4T1 and CT26 cells as detected by ELISA (Fig. 1d). The inhibition of AGT expression significantly decreased AngII levels in the supernatant of these cultured tumor cells under both normoxic and hypoxic condition (Fig. 1d). Similar to ATR blockage, AGT silencing did not influence cell proliferation in vitro as detected by MTT assay (Fig. 1e) and tumor growth in our immunodeficient mouse model (NOD/SCID mice) (Additional file 1: Figure S2A and B). However, AGT silencing in these cells clearly inhibited the tumor growth in 4T1 breast cancer and CT26 colon cancer in BALB/c mice with normal immune systems (Fig. If and Additional file 1: Figure S2C). Furthermore, we conducted a CD8 $\mathrm{T}$ cell depletion experiment by in vivo administration of a monoclonal antibody against CD8 and found that the differential tumor growth in $\mathrm{BALB} / \mathrm{c}$ mice disappeared for both $4 \mathrm{~T} 1$ and CT26 cells 


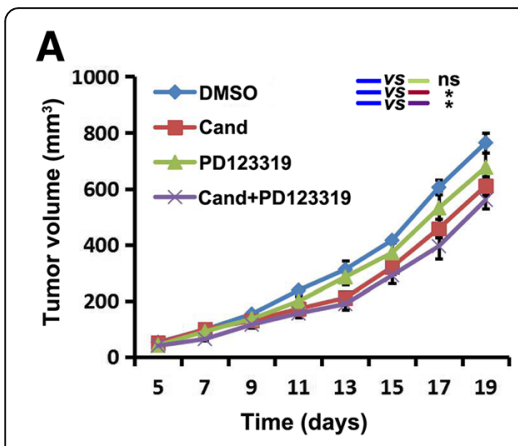

D

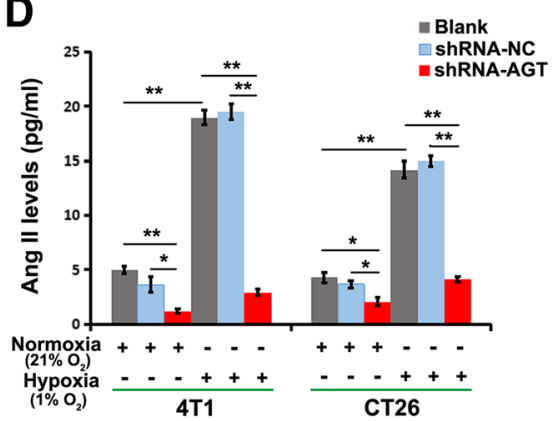

B

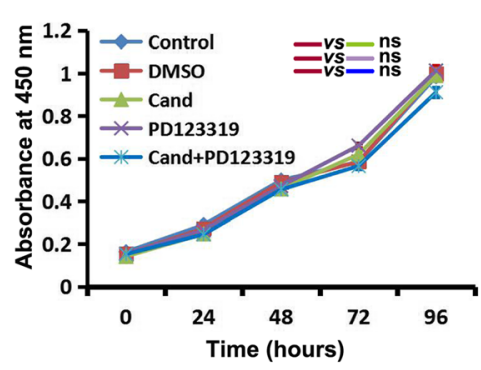

E

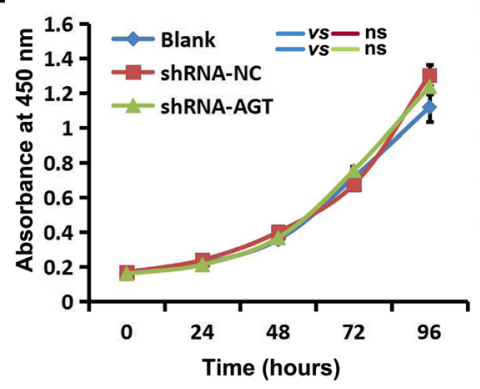

C

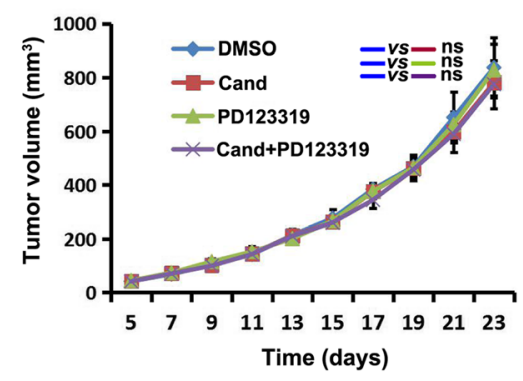

$\mathbf{F}$

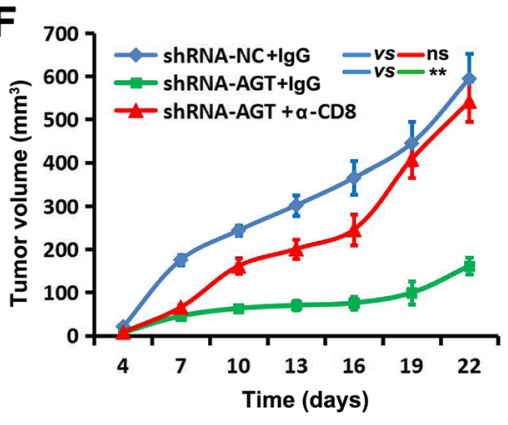

Fig. 1 Local Angll in tumor microenvironment is involved in immune escape of tumor cells. a The influence of Angll-receptor blockers on 4T1 tumor growth in syngeneic BALB/c mice; candesartan (cand, $5 \mathrm{mg} / \mathrm{kg}$, i.p.; starting at day 5 after cell injection, daily ) for AT1R and PD123319 (5mg/kg, i.p.; starting from day 5 after cell injection, every other day) for $A T 2 R, n=5$. $\mathbf{b}$ The influence of Angll-receptor blockers on 4T1 cells proliferation in vitro as

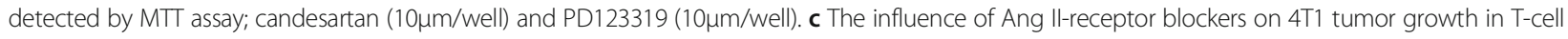
immunodeficient BALB/c nude mice, $n=5$. $\mathbf{d}$ The expression of AGT, a precursor of Angll, was silenced in $4 \mathrm{~T} 1$ cells and $\mathrm{CT} 26$ cells by shRNA. Hypoxia remarkably induced generation of Ang II in $4 \mathrm{~T} 1$ and CT26 cells as detected by ELISA. AGT-silencing greatly decreased Ang II levels, especially under hypoxic condition. Data are presented as mean $\pm \mathrm{SEM}, n=3$. e AGT silencing did not influence cell-proliferation of $4 \mathrm{~T} 1$ cells in vitro as detected by MTT assay. $\mathbf{f}$ AGT silencing obviously inhibited tumor growth of 4T1cells in BALB/c mice comparing to negative control, and the depletion of CD $8^{+} T$ cells in mice by in vivo administration of monoclonal antibody against CD8 greatly attenuated this effect $(n=6)$. Ns, no significance; ${ }^{*}, P<0.05 ;{ }^{* *}, P<0.01$

(Fig. 1f and Additional file 1: Figure S2C). These results indicate that AngII may contribute to immune escape of $4 \mathrm{~T} 1$ or CT26 cells in BALB/c mice through suppressing a CD8 T-cell mediated anti-tumor immune response.

\section{Angll signaling blockage sensitizes tumors to checkpoint immunotherapy}

Because it has been well-documented that 4T1 tumors are highly resistant to PD1 and CTLA-4 checkpoint immunotherapy $[26,30]$, we sought to determine whether an AngII signaling blockage could enhance the response of 4T1 tumors to checkpoint immunotherapy. BALB/c mice with $4 \mathrm{~T} 1$ tumors were repeatedly treated by intraperitoneal injection (i.p.) with anti-PD-1 or anti-CTLA-4 antibodies as single agents or in combination with candesartan. We did not observe any significant inhibition of tumor growth when they were treated with anti-PD-1 or anti-CTLA-4 alone (Fig. 2a ). Interestingly, candesartan could remarkably improve the effect of these immune checkpoint blockers on 4T1 tumors (Fig. 2a ) and prolonged the survival of $4 \mathrm{~T} 1$ tumor-bearing mice (Fig. $2 \mathrm{~b}$ ). To further verify this effect of AngII signaling blockage on checkpoint immunotherapy, BALB/c mice bearing
AGT-silenced 4T1 tumors were also treated by intraperitoneal injection of anti-PD-1 antibody (Additional file 1: Figure S3). After four administrations of anti-PD-1 antibody, all observable tumors derived from AGT-silenced 4T1 cells completely disappeared (Fig. 2c and Additional file 1: Figure S4A). More importantly, no recurrence was noted in these mice which have achieved long-term survival over one-year of observation (Fig. 2d). Similar results were obtained in the CT26 colon tumor model in syngeneic BALB/c mice (Additional file 1: Figure S4B). These results suggest that Ang II signaling blockage sensitizes tumors to checkpoint immunotherapy in mouse models.

\section{Angll signaling blockage reverses the immunosuppressive tumor microenvironment}

To explore the potential mechanism by which an AngII signaling blockage enhances tumor responses to checkpoint immunotherapy, we first performed multicolor flow cytometry analysis (FACS) to detect the proportions of effector $\mathrm{T}$ cells $\left(\mathrm{T}_{\text {effs }}\right)$ and regulatory $\mathrm{T}$ cells $\left(\mathrm{T}_{\text {regs }}\right)$ in $4 \mathrm{~T} 1$ breast tumors from $\mathrm{BALB} / \mathrm{c}$ mice treated with Ang II-receptor blockers. We found that candesartan significantly increased the frequencies of $\mathrm{CD}^{+} \mathrm{T}$ cells in 

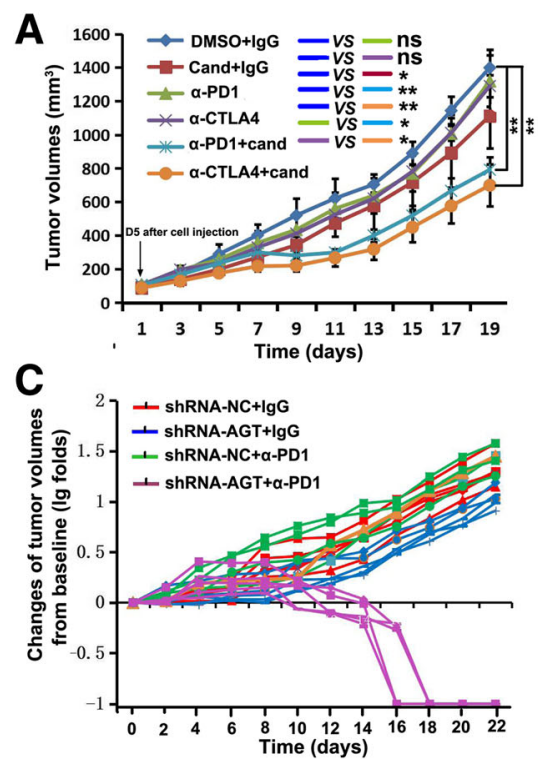

B

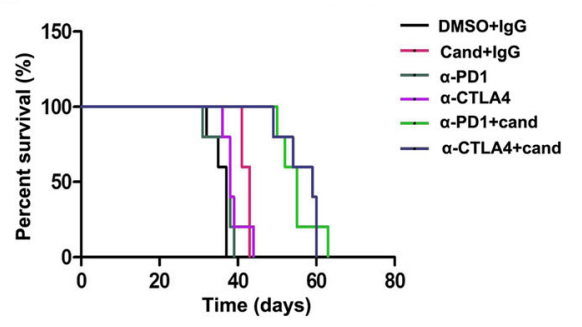

D

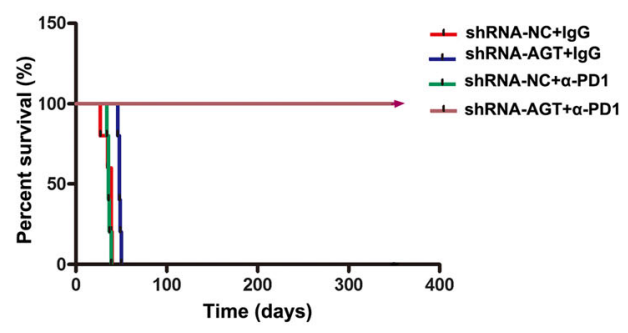

Fig. 2 Angll signaling blockage sensitizes tumors to checkpoint immunotherapy in mice tumor models. a No significant inhibition of tumor growth when treated with anti-PD-1(a-PD1) or anti-CTLA-4 (a-CTLA4) alone; however, candesartan remarkably improved the effect of immune checkpoint blockers on $4 \mathrm{~T} 1$ tumors ( $n=5$ ); ATR blockers and checkpoint inhibitors were administered starting from day 5 after cell injection. b Checkpoint immunotherapy combined with candesartan significantly prolonged the survival of 4T1 tumor-bearing mice ( $n=5$ ). c AGT gene-silencing (shRNA-AGT) in 4T1 cells rendered tumors completely responsive to PD1 checkpoint immunotherapy; negative control: shRNA-NC. $\mathbf{d}$ AGT gene-silencing in 4T1 tumors combined with PD1 immunotherapy made all of mice $(n=5)$ achieve long-term survival without any recurrence during almost one-year observation. Ns, no significance; ${ }^{*}, P<0.05 ;{ }^{* *}, P<0.01$

4T1 tumors (Additional file 1: Figure S5A). More importantly, candesartan remarkably increased the frequencies of $\mathrm{CD} 8^{+} \mathrm{CD} 44^{+} \mathrm{T}_{\text {eff }}$ cells and decreased that of CD $4^{+}$Foxp $3^{+} \mathrm{T}_{\text {reg }}$ cells in $4 \mathrm{~T} 1$ tumors (Fig. 3a), leading to an increased $\mathrm{T}_{\text {effs }} / \mathrm{T}_{\text {regs }}$ ratio (Fig. $3 b$ ). Similar results were also observed in tumors treated with a combination of candesartan and PD123319. However, PD123319 alone did not increase the frequencies of $\mathrm{T}_{\text {eff }}$ cells in tumors, but it non-significantly decreased the frequency of $\mathrm{T}_{\text {reg }}$ cells compared to the control tumors (Fig. 3a and b). Furthermore, AGT expression suppression in tumor cells had the same impact on tumor infiltrating $\mathrm{T}$ cells as the candesartan treatment (Additional file 1: Figure S6). These results indicate that AngII signaling, predominantly Ang II-AT1R-mediated signaling, may be involved in forming a tumor immunosuppressive microenvironment .

Since the pathogenesis of AngII in chronic organ diseases is largely mediated by inducing the infiltration and activation of fibroblasts $[17,18]$ and macrophages $[19,20]$, we sought to examine whether AngII mediates infiltration and activation of fibroblasts and macrophages in $4 \mathrm{~T} 1 \mathrm{tu}-$ mors. Immunofluorescence analysis showed many $\alpha$-smooth muscle actin ( $\alpha$-SMA)-positive fibroblasts and fewer CD8-positive T cells in 4T1 breast tumors, especially in pimonidazole-positive ( a probe for tumor hypoxia ) hypoxic regions (Fig. 3c and Additional file 1: Figure S7 ). However, AGT-silencing remarkably inhibited the infiltration of fibroblasts and increased the number of
CD8-positive T cells in 4T1 tumors (Fig. 3c and Additional file 1: Figure S7). We further measured fibrosis of $4 \mathrm{~T} 1$ tumors and found a high degree of collagen fiber deposition in $4 \mathrm{~T} 1$ breast tumors (Fig. 3d). Interestingly, candesartan abated collagen fiber deposition in $4 \mathrm{~T} 1$ tumors as detected by Sirius Red staining (Fig. 3d).

We also found that there was an a decrease in CD206-positive (a marker of mouse M2-phenotype TAMs) cells in pimonidazole-positive hypoxic regions of 4T1 tumors upon ATG silencing (Fig. 3c and Additional file 1: Figure S7). These results indicate that AngII signaling could be involved in infiltration of TAMs in tumors. Next, we used multicolor flow cytometry to analyze the content of TAMs $\left(\mathrm{CD} 45^{+} \mathrm{CD} 11 \mathrm{~b}^{+} \mathrm{F} 4 / 80^{+} \mathrm{CD} 206^{+}\right)$in $4 \mathrm{~T} 1$ tumors. We found that candesartan treatment significantly inhibited the accumulation of macrophages $\left(\mathrm{CD} 45^{+} \mathrm{CD} 11 \mathrm{~b}^{+} \mathrm{F} 4 / 80^{+}\right)$and TAMs in 4T1 tumors compared to tumors from control mice without candesartan treatment (Fig. 3e and g, and Additional file 1: Figure S5B). We also found that the frequency of monocytic myeloid-derived suppressor cells (Mo-MDSCs, CD $45^{+}$CD $11 b^{+}{ }^{+} y 6 G^{\text {low }}{ }^{2 y} 6 C^{\text {high }}$ ) remarkably decreased in candesartan-treated tumors compared to those from control mice, and however, the decrease in the proportions of granulocytic myeloid-derived suppressor cells (G-MDSCs) in tumors upon candesartan treatment was non-significant (Fig. $3 \mathrm{f}$ and $\mathrm{g}$, and Additional file 1: Figure S5C). Consistently, we observed that in AGT-silenced 4T1 tumors, the number of TAMs 





(See figure on previous page.)

Fig. 3 Angll signaling blockage reverses immunosuppressive tumor microenvironment. a Representative FACS plot of $\mathrm{T}_{\text {eff }}\left(C D 8^{+} \mathrm{CD} 44^{+}\right)$and $\mathrm{T}_{\text {reg }}$ $\left(\mathrm{CD}^{+} \mathrm{Foxp3}^{+}\right)$in $4 \mathrm{~T} 1$ breast tumors from BALB/c mice treated with different Ang II-receptor blockers. Bar chart (right) indicated statistic difference $(* *, P<$ 0.01; ns, no significance). Data are presented as mean $\pm S E M, n=3$. b Bar chart indicated $T_{\text {eff }} / T_{\text {reg }}$ rate $(* *, P<0.01)$. Data are presented as mean $\pm S E M, n=3$. $\mathbf{c}$ Immunofluorescence analysis showed lots of a-SMA positive fibroblasts and less CD8-positive T cells in hypoxic regions ( pimonidazole-positive ) of 4T1 tumors. AGT gene silence in 4T1 cells obviously inhibited the infiltration of fibroblasts and increased CD8-positive T cells. There were an accumulation of CD206-positive (a marker of mouse M2-phenotype TAMs) cells in pimonidazole-positive hypoxic regions of 4T1 tumors while AGT gene silence remarkably decreased the infiltration of CD206-positive cells in 4T1 tumors, especially in hypoxic regions. d Candesartan abated collagen fiber deposition in 4T1 tumors as detected by Sirius Red staining. e Representative FACS plot of TAMs $\left(C D 45^{+} \mathrm{CD} 11 \mathrm{~b}^{+} \mathrm{F} 4 / 80^{+} \mathrm{CD} 206^{+}\right)$in $4 \mathrm{~T} 1$ tumors with or without candesartan

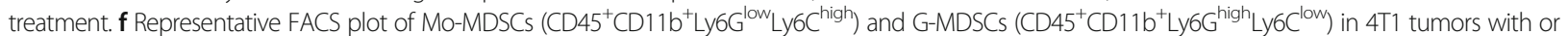
without candesartan treatment. $\mathbf{g}$ Bar chart indicated the percentages of TAMs, Mo-MDSCs and G-MDSCs in 4 T1 tumors $(* *, P<0.01)$. Data are presented as mean $\pm \mathrm{SEM}, n=3$

obviously decreased compared with control $4 \mathrm{~T} 1$ tumors (Additional file 1: Figure S8A and C ). Notably, AGT-silenced 4T1 tumors exhibited decreased percentages of both Mo-MDSCs and G-MDSCs, compared to control 4T1 tumors (Additional file 1: Figure S8B and C). These results further support our hypothesis that local AngII contributes to the formation of a tumor immunosuppressive microenvironment and the AngII signaling blockage reverses it into an immune-activating microenvironment.

\section{Inhibition of AGT expression strongly triggers an immune-activating cytokine profile in hypoxic 4T1 cells}

Accumulating evidence has revealed that intratumor hypoxia contributes to tumor immune escape by altering the function of innate and adaptive immune cells or by increasing the intrinsic resistance of tumor cells to cytolytic activity of immune effectors [31-33]. To demonstrate the mechanism of immune activation by AngII signaling blockage, cytokine profiles (containing 308 cytokines) of 4T1 cells in normoxia or hypoxia were analyzed using the RayBio Mouse Cytokine Antibody Array. Hypoxia induced obvious alterations ( more than 2 folds ) of 64/308 cytokines expression, in which 14 cytokines decreased and 50 increased (more than 2-fold changes) (Fig. 4a). Notably, AGT silencing remarkably altered expression of 65 cytokines in 4T1 hypoxic cells compared with control hypoxic cells. In these 65 cytokines, 45 cytokines were obviously decreased (more than 2 folds) and 20 were increased (more than 2 folds) in hypoxic AGT-silenced 4T1 cells (Fig. 4a). Interestingly, the cytokines altered by AGT-silencing were largely overlapped with those influenced by hypoxia exposure (Fig. 4b). To verify the reliability of the cytokine array data, we further used ELISA analysis to detected the levels of 6 defferential cytokines (IL-10, GM-CSF, G-CSF, Eotaxin-2, CXCL11, and TNFSF14) in the culture supernatant of 4T1 cells under different $\mathrm{O}_{2}$ conditions, and results consistent with the cytokine array were obtained for all of 6 cytokines (Additional file 1: Figure S9A).

To investigate functional relationships of the altered cytokines, Gene Ontology (GO) analysis was used to organize the cytokine array data into their functional relationships based on biologic processes and pathways. Hypoxia induced significantly higher frequencies of cytokines which were associated with 39 biological processes $(p<0.01)$ (Additional file 1: Figure S9B) and 17 signaling pathways $(p<0.05)$ (Additional file 1: Figure S9D). On the other hand, the cytokines altered by AGT-silencing in hypoxia were associated with 58 biological processes $(p<0.01)$ (Additional file 1: Figure S9C) and 22 signaling pathways $(p<0.05)$ (Additional file 1: Figure S9D). Notably, hypoxia particularly influenced immune response ( $p=9.54 \mathrm{E}-18$ ) (Fig. 4c), leading to a decreased expression of immune-activating cytokines and an increased expression of immunosuppressive cytokines (Fig. 4d). It is worth noting that AGT silencing also prominently impacted the immune response with differential expression $(p=2.04 \mathrm{E}-20)$ of 20 cytokines (Fig. 4c). Seven of these 20 cytokines, namely, IL-7, IL-20, CD40 ligand, CXCL1, CXCL11, TNFSF12 and TNFSF14, which have been previously reported to be immune-activating cytokines (Fig. $4 \mathrm{~d}$ and Table 1), had a remarkably increased expression (changes $>2$ fold). In contrast, 11 of these 20 cytokines, namely, IL-3, IL-10, IL-4, Fas, Fas ligand (FASL), CCL1, CCL7, CCL28, G-CSF, GM-CSF and Eotaxin-2, which have been previously reported to be immunosuppressive cytokines (Fig. 4d and Table 1), had a significantly decreased expression (changes $>2$ fold). These results suggest that hypoxia contributes to the formation of an immunosuppressive microenvironment, and AGT silencing, however, reverses this immunosuppressive status and induces an immune-activating anti-tumor microenvironment.

\section{AGT silencing combined with PD-1 blockage generates an abscopal effect to resistant tumors}

To investigate whether the improved immune microenvironment in a tumor would contribute to the response of other tumors in the same mouse, 4T1 cells with AGT silencing and a negative control (NC) were respectively injected into two sides (bilateral) of mammary fat pads in BALB/C mice (Fig. 5a). We found that AGT-silenced tumors did not influence the growth of 


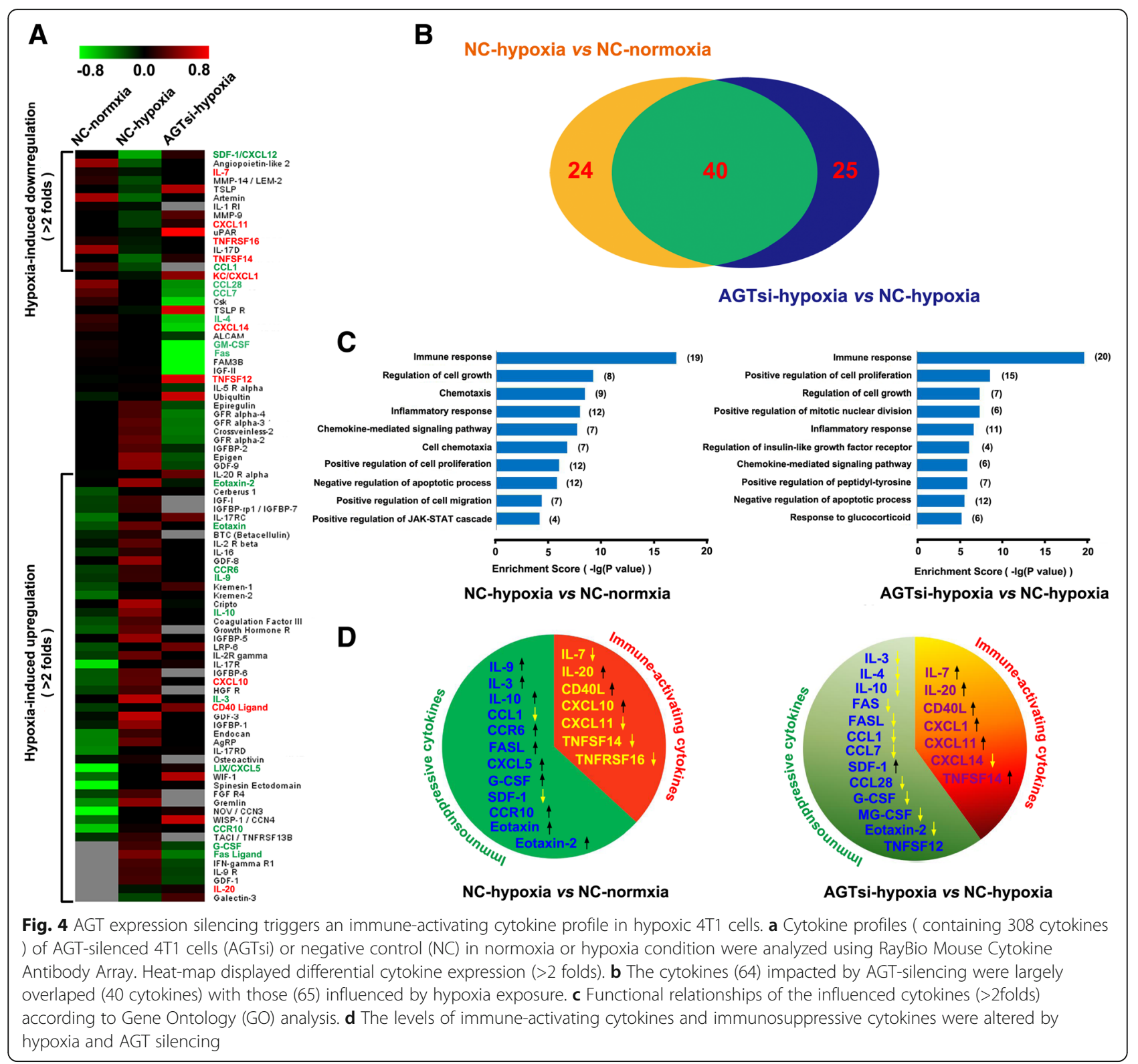

contralateral $\mathrm{NC}$ tumors in bilaterally-injected mice (Fig. 5b). However, when anti-PD-1 antibody was administrated to bilaterally-injected mice by i.p. injection, NC-tumor growth in the same mice was remarkably inhibited, with $\mathrm{NC}$ tumors in three of six mice completely disappearing (Fig. 5b). These results suggests that AGT silencing in tumor combined with system PD-1 blockage results in an abscopal effect on other tumor focuses that were originally resistant to PD-1 blockage in mice.

\section{Discussion}

Currently, immunotherapy by checkpoint inhibition holds great promise for improving cancer patient outcomes, as it has done for patients with melanoma [34] or lung cancer [35]. Unfortunately, checkpoint inhibitors have only achieved limited clinical benefit to date for most malignant tumors, likely due to multiple immune escape mechanisms mediating cancer resistance to immunotherapy [6].

Fibrosis and infiltration of multiple immune suppressor cells in tumors have been suggested as important mechanisms by which a tumor immunosuppressive microenvironment is established in many kinds of human tumors [6], especially in breast cancer [36, 37] and pancreatic cancer $[38,39]$, which are commonly resistant to current anti-checkpoint immunotherapy. Recent studies have demonstrated that hypoxia plays a critical role in the formation of a tumor immunosuppressive microenvironment by multiple mechanisms [40], but predominantly by 

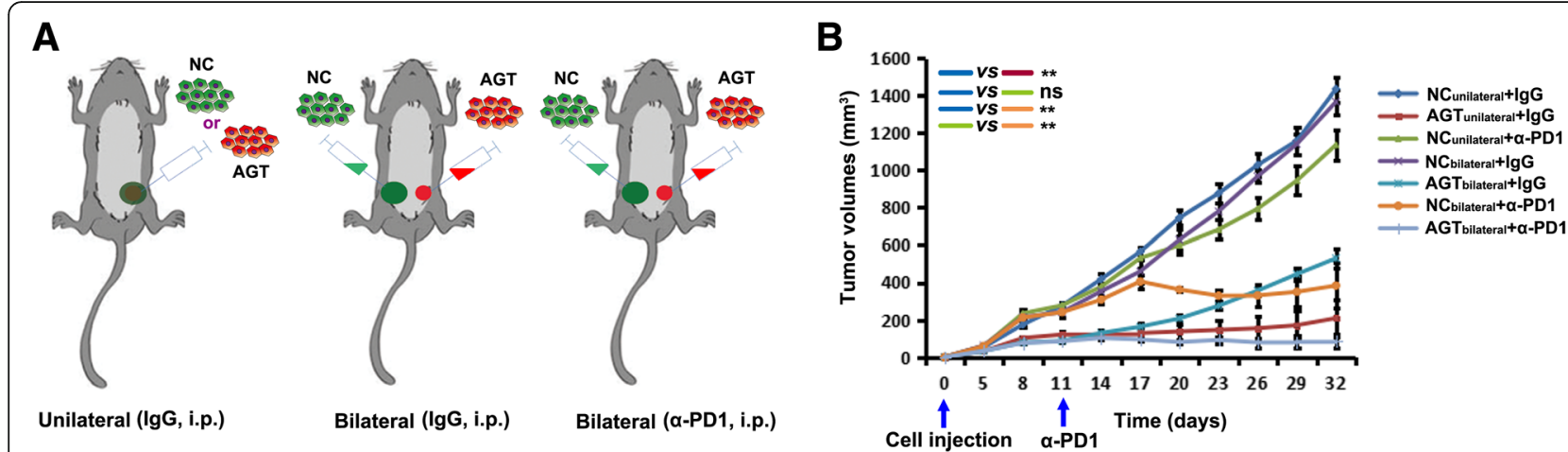

Fig. 5 An abscopal effect on resistant tumors is induced by AGT silencing in local tumor combined with PD-1 blockage. a AGT-silenced 4T1 cells (AGT) and negative control (NC) were injected into single (unilateral) or two sides (bilateral) respectively of mammary fat pads in BALB/c mice. $\mathbf{b}$ $4 \mathrm{~T} 1$ tumor-bearing mice were treated as indicated. The volume of each tumor was measured from each mouse $(n=6)$. Ns, no significance; ${ }^{* *}, P$ $<0.01$

increasing the infiltration of CAFs and TAMs in hypoxic tumor areas [40-42]. Our previous report showed that local AngII existed in a tumor hypoxic microenvironments where AngII was produced by hypoxic tumor cells in a hypoxia-lactate-chymase-dependent mechanism, independent from the AngII in the blood circulation system [16]. Herein, using a mouse 4T1 breast cancer model and CT26 colon cancer model, we revealed that AngII generated by hypoxic tumor cells had an important role in forming a tumor immunosuppressive microenvironment.

Other previous studies have shown that AngII could induce the infiltration and activation of fibroblasts and some inflammatory cells, and thus resulted in a variety of chronic organ diseases [17-20]. We hypothesize that the AngII present in tumors may function similarly, and it therefore mediates the recruitment and activation of fibroblasts and inflammatory cells in the tumor microenvironment to support immunosuppression. Herein we found that AngII induced the infiltration of fibroblasts and macrophages into a tumor microenvironment, and the abrogation of AngII generation or AngII signal blockage decreased the infiltration of fibroblasts and macrophages and contributed to $\mathrm{CD} 8^{+} \mathrm{T}$ cell infiltration into tumor regions. These results suggest that AngII seems to play a similar function in tumors as in chronic organ diseases, resulting in an intratumor immunosuppressive microenvironment. A high-content cytokine array ( including 308 cytokines ) analysis showed hypoxia induced an immunosuppressive cytokine profile; however, AGT silencing re-established an immune-activating cytokine profile for hypoxic 4T1 breast cancer cells. Therefore, AngII may confer to these tumor cells the ability to create an immunosuppressive microenvironment so as to escape immune elimination.

AngII signal blockage or AGT expression silencing in tumor cells destroys the tumor immunosuppressive microenvironment and improves the tumor response to immune checkpoint inhibitors. Interestingly, silencing AGT expression in 4T1 cells achieved a long-term tumor remission in all of the mice treated with PD-1 checkpoint inhibitor and induced a relapse-free survival. More importantly, 4T1 mouse tumors with AGT expression silencing made a previously unresponsive control tumor, growing on other site of the mouse, achieve a dramatic response to checkpoint antagonists. These results suggest that the alteration of the immune microenvironment in a local tumor through AGT silencing can trigger a systemic anti-tumor immune response although anti-PD-1 is required to eliminate the tumor cells. A possible mechanism for this is that the destruction of the local immunosuppressive microenvironment contributes to tumor antigen presentation and consequently activates multiple antigen-specific effector $\mathrm{T}$ cells which are capable of specifically attacking tumor cells at any sites in the body when combined with anti-PD-1 therapy. AGT silencing in hypoxic 4T1 cells triggered an immune-activating cytokine profile, including some cytokines involved in attracting, activating, and stimulating proliferation of dendritic cells and $T$ cells [43-49], which contributes to tumor antigen presentation and generation of multiple tumor-antigen-specific effector $\mathrm{T}$ cells. Therefore, the altered immune microenvironment in a local tumor by AGT expression-silencing may elicit an in situ tumor vaccination and generate productive tumor-specific $\mathrm{T}$ cells to achieve a systemic in vivo anti-tumor effect. Given the role of AngII signaling in inhibiting HIF- $1 \alpha$ protein accumulation in hypoxia tumors [16], another possible mechanism of the benefit from an AngII signaling blockade (both genetic and pharmacological) is that an AngII signaling blockade sensitizes these tumors to effective $\mathrm{T}$ cell-mediated killing because hypoxia-induced HIF-1alpha has been shown to prevent CTL-mediated killing [50, 51]. 
A recently published article by Nakai showed that candesartan failed to improve survival in those patients receiving gemcitabline-based combination chemotherapy [52]. However, a subgroup analysis showed that patients receiving gemcitabine monotherapy could benefit from candesartan [15]. A possible explanation for the negative results by Nakai is that excessive combination chemotherapy profoundly impairs patients' immune system, due to drug-cytotoxicity acting on normal immune cells, which could overwhelm any benefit from candesartan.

\section{Conclusions}

In the present study, we demonstrated that local AngII contributed to the formation of a tumor immunosuppressive microenvironment that mediated tumor resistance to current checkpoint immunotherapy. AngII signal blockage or abrogating AngII generation in tumor cells remarkably enhanced the effect of anti-checkpoint immunotherapy in BALB/c mice with a normal immune system. A combination of AngII signal blocker with a checkpoint antagonist could be a promising strategy to improve tumor responses to current anti-checkpoint immunotherapy.

\section{Additional file}

Additional file 1: Figure S1. The efficacy of knockdown was detected through qRT-PCR and western blotting. The efficacy of knockdown in 4T1 cells (A) and CT26 cells (B). Figure S2. Role of AGT gene-silencing in growth of 4T1 and CT26 cells. AGT-silencing didn't significantly inhibit tumor growth of 4T1 (A) and CT26 cells (B) in NOD/SCID mice. (C) AGT silencing inhibited CT26 growth in BALB/C mice and the depletion of $\mathrm{CD}^{+} \mathrm{T}$ cells reversed this role. Figure S3. Strategy of combined AGT gene-silencing and PD1 blockade. Figure S4. Angll signaling blockage sensitizes tumors to checkpoint immunotherapy. AGT gene-silencing in 4T1 (A) and CT26 cells (B) rendered tumors more sensitive to anti-PD1 immunotherapy. Figure S5. Percentages of $\mathrm{CD}^{+}, \mathrm{CD}_{4} 5^{+}$, and $\mathrm{CD} 11 \mathrm{~b}^{+}$ cells in $4 \mathrm{~T} 1$ tumors from BALB/c mice treated with different Ang 11 -receptor blockers. (A), (B), and (C) correspond to Figure $\mathbf{3 A}, \mathbf{3 E}$, and 3F. Figure S6. Representative FACS plot of $\mathrm{T}_{\text {effs }}\left(\mathrm{CD} 8^{+} \mathrm{CD} 44^{+}\right)$and $\mathrm{T}_{\text {regs }}\left(\mathrm{CD} 4^{+} \mathrm{Foxp} 3^{+}\right)$in AGT-silenced and control 4T1 tumors from BALB/c mice. Bar chart (right) indicated statistic difference $(n=3)$. Figure S7. a-SMA, CD8 or CD206 positive cells in hypoxic regions of $4 \mathrm{~T} 1$ tumors. Positive cells were counted in 4 random $400 \times$ microscope visions in hypoxic regions of AGT-silenced or control tumors which were from 3 independent mice, $(n=12)$. Figure $\mathbf{S 8 .}$ The content of TAMs, Mo-MDSCs and G-MDSCs in shRNA-AGT 4T1 tumors. (A-B) Representative FACS plot. (C) Percentages of these populations $(n=3)$. Figure S9. AGT-silencing triggers an immune-activating cytokine profile in hypoxic 4T1 cells. The levels of 6 cytokinesby ELISA analysis (A). Gene Ontology analysis showed hypoxia induced significantly higher frequencies of cytokines which were associated with 39 biological processes $(\mathrm{B}, p<0.01)$ and 17 signaling pathways $(\mathrm{D}$, left, $p<0.05)$. The cytokines influenced by AGT-silencing in hypoxia condition were associated with 58 biological processes $(C, p<0.01)$ and 22 signaling pathways $(D$, right, $p<0.05$ ). Table S1. Antibodies for Immunofluorescence. (DOCX 48272 kb)

\section{Abbreviations}

ACE: Angiotensin-converting enzyme; AGT: Angiotensinogen; Angll: Angiotensin II; AT1R: Angll type 1 receptor; AT2R: Ang II type 2 receptor; CAFs: Cancer-associated fibroblasts; CTLA-4: Cytotoxic-Tlymphocyte-associated protein 4; G-MDSCs: Granulocytic myeloid-derived suppressor cells; GO: Gene Ontology; Mo-MDSCs: monocytic myeloid-derived suppressor cells; NC: Negative control; PD-1: Programmed cell death protein 1; RAS: Renin-angiotensin system; shRNA: Short hairpin RNA; TAMs: Tumorassociated macrophages; $T_{\text {effs: }}$ : Effective $T$ cells; $T_{\text {regs: }}$ : Regulatory $T$ cells; $a-$ SMA: a-smooth muscle actin

\section{Acknowledgements}

We thank Meijuan Chen in the Department of of Infectious Disease and Hepatology Unit for the flow cytometry. We thank KangChen Bio-tech (Shanghai, China) for the mouse cytokine antibody array analysis of the 4T1 mouse breast cancer cells.

\section{Funding}

This work was supported by the National Natural Science Foundation of China Grants (81672633, 81572964 and 81773354), Science and Technology Projects of Guangdong Province (2017A020215171), Major Science and Technology Projects in Guangdong Province (2015B090922014 and 2016B030306004), Natural Science Foundation of Guangdong Grant (2014A030313289) and Science and Technology Projects of Guangzhou (201604016041). It was also supported by the Outstanding Youths Development Scheme of Nanfang Hospital, Southern Medical University.

\section{Availability of data and materials}

All data generated or analyzed during this study are included in this article and its Additional file 1.

\section{Authors' contributions}

GX, TC and JL performed ELISA, immunofluorescence, flow cytometry, Sirius Red staining and in vivo animal experiment. LZ, JZ, YL and BW performed cell culture, construction of the RNAi lentiviral vector and establishment of the AGT-silenced cells. GX analyzed the data and performed the statistics analysis. GX and YY designed the experiments, wrote the manuscript and contributed to the discussion of the results. All authors read and approved the final manuscript.

\section{Ethics approval and consent to participate}

All experimental procedures were approved and overseen by the Southern Medical University Institutional Animal Care and Use Committee and were performed in accordance with the guidelines and regulations for animal experiments set down by Southern Medical University.

\section{Consent for publication}

Not applicable.

\section{Competing interests}

The authors declare that they have no competing interests.

\section{Publisher's Note}

Springer Nature remains neutral with regard to jurisdictional claims in published maps and institutional affiliations.

\section{Author details}

${ }^{1}$ Department of Radiation Oncology, Nanfang Hospital, Southern Medical University/The First School of Clinical Medicine, Southern Medical University, Guangzhou 510515, Guangdong, China. Department of Radiation Oncology, Affiliated Cancer Hospital \& Institute of Guangzhou Medical University, Guangzhou 510095, Guangdong, China. ${ }^{3}$ Department of Hepatopancreas Surgery, the First People's Hospital of Foshan, Foshan 528000, Guangdong, China. ${ }^{4}$ School of Computer Science and Technology, Guangdong University of Technology, Guangzhou 510006, China.

Received: 3 July 2018 Accepted: 24 August 2018

Published online: 12 September 2018

\section{References}

1. Khalil DN, Smith EL, Brentjens RJ, Wolchok JD. The future of cancer treatment: immunomodulation, CARs and combination immunotherapy. Nat Rev Clin Oncol. 2016;13:394.

2. Chen DS, Mellman I. Elements of cancer immunity and the cancer-immune set point. Nature. 2017;541:321-30.

3. Jenkins RW, Barbie DA, Flaherty KT. Mechanisms of resistance to immune checkpoint inhibitors. Br J Cancer. 2018;118:9-16. 
4. Pitt JM, Vetizou M, Daillere R, Roberti MP, Yamazaki T, Routy B, et al. Resistance Mechanisms to Immune-Checkpoint Blockade in Cancer: TumorIntrinsic and -Extrinsic Factors. Immunity. 2016;44:1255-69.

5. Pulluri B, Kumar A, Shaheen M, Jeter J, Sundararajan S. Tumor microenvironment changes leading to resistance of immune checkpoint inhibitors in metastatic melanoma and strategies to overcome resistance. Pharmacol Res. 2017;123:95-102.

6. Joyce JA, Fearon DT. T cell exclusion, immune privilege, and the tumor microenvironment. Science. 2015;348:74-80

7. George AJ, Thomas WG, Hannan RD. The renin-angiotensin system and cancer: old dog, new tricks. Nat Rev Cancer. 2010;10:745-59.

8. de Gasparo M, Catt KJ, Inagami T, Wright JW, Unger T. International union of pharmacology. XXIII. The angiotensin II receptors. Pharmacol Rev. 2000;52:415-72.

9. Campbell DJ. Clinical relevance of local Renin Angiotensin systems. Front Endocrinol (Lausanne). 2014:5:113.

10. Imanishi M, Tomita S, Ishizawa K, Kihira Y, Ueno M, Izawa-Ishizawa Y, et al. Smooth muscle cell-specific Hif-1alpha deficiency suppresses angiotensin II-induced vascular remodelling in mice. Cardiovasc Res. 2014;102:460-8.

11. Heilig CW, Deb DK, Abdul A, Riaz H, James LR, Salameh J, et al. GLUT1 regulation of the pro-sclerotic mediators of diabetic nephropathy. Am J Nephrol. 2013;38:39-49.

12. Kim JH, Kim JH, Yu YS, Cho CS, Kim KW. Blockade of angiotensin II attenuates VEGF-mediated blood-retinal barrier breakdown in diabetic retinopathy. J Cereb Blood Flow Metab. 2009;29:621-8.

13. Lever AF, Hole DJ, Gillis CR, McCallum IR, McInnes GT, MacKinnon PL, et al. Do inhibitors of angiotensin-I-converting enzyme protect against risk of cancer? Lancet. 1998;352:179-84.

14. Nakai $Y$, Isayama $H$, ljichi $H$, Sasaki T, Kogure $H$, Yagioka $H$, et al. Phase I trial of gemcitabine and candesartan combination therapy in normotensive patients with advanced pancreatic cancer: GECA1. Cancer Sci. 2012;103: 1489-92.

15. Nakai $Y$, Isayama $H$, Sasaki T, Takahara N, Saito K, Ishigaki K, et al. The inhibition of renin-angiotensin system in advanced pancreatic cancer: an exploratory analysis in 349 patients. J Cancer Res Clin Oncol. 2015;141:933-9.

16. Xie G, Liu Y, Yao Q, Zheng R, Zhang L, Lin J, et al. Hypoxia-induced angiotensin II by the lactate-chymase-dependent mechanism mediates radioresistance of hypoxic tumor cells. Sci Rep. 2017;7:42396.

17. Chen G, Lin SC, Chen J, He L, Dong F, Xu J, et al. CXCL16 recruits bone marrow-derived fibroblast precursors in renal fibrosis. J Am Soc Nephrol. 2011;22:1876-86.

18. Xia Y, Yan J, Jin X, Entman ML, Wang Y. The chemokine receptor CXCR6 contributes to recruitment of bone marrow-derived fibroblast precursors in renal fibrosis. Kidney Int. 2014;86:327-37.

19. Nobuhiko A, Suganuma E, Babaev VR, Fogo A, Swift LL, Linton MF, et al. Angiotensin II amplifies macrophage-driven atherosclerosis. Arterioscler Thromb Vasc Biol. 2004;24:2143-8.

20. Suganuma E, Zuo Y, Ayabe N, Ma J, Babaev VR, Linton MF, et al. Antiatherogenic effects of angiotensin receptor antagonism in mild renal dysfunction; 2006.

21. Yang $L$, Zhang $Y$. Tumor-associated macrophages: from basic research to clinical application. J Hematol Oncol. 2017;10:58.

22. Grivennikov SI, Greten FR, Karin M. Immunity, inflammation, and cancer. Cell. 2010;140:883-99.

23. Noy R, Pollard JW. Tumor-associated macrophages: from mechanisms to therapy. Immunity. 2014;41:49-61.

24. Williams $C B$, Yeh ES, Soloff AC. Tumor-associated macrophages: unwitting accomplices in breast cancer malignancy. NPJ Breast Cancer. 2016;2:15025.

25. Zhong X, Chen B, Yang Z. The Role of Tumor-Associated Macrophages in Colorectal Carcinoma Progression. Cell Physiol Biochem. 2018;45:356-65.

26. Kim K, Skora AD, Li Z, Liu Q, Tam AJ, Blosser RL, et al. Eradication of metastatic mouse cancers resistant to immune checkpoint blockade by suppression of myeloid-derived cells. Proc Natl Acad Sci U S A. 2014;111:11774-9.

27. De Henau O, Rausch M, Winkler D, Campesato LF, Liu C, Cymerman DH, et al. Overcoming resistance to checkpoint blockade therapy by targeting PI3Kgamma in myeloid cells. Nature. 2016;539:443-7.

28. Zheng X, Carstens JL, Kim J, Scheible M, Kaye J, Sugimoto H, et al. Epithelialto-mesenchymal transition is dispensable for metastasis but induces chemoresistance in pancreatic cancer. Nature. 2015;527:525-30.

29. Twyman-Saint VC, Rech AJ, Maity A, Rengan R, Pauken KE, Stelekati E, et al. Radiation and dual checkpoint blockade activate non-redundant immune mechanisms in cancer. Nature. 2015;520:373-7.
30. Bertrand F, Montfort A, Marcheteau E, Imbert C, Gilhodes J, Filleron T, et al. TNFalpha blockade overcomes resistance to anti-PD-1 in experimental melanoma. Nat Commun. 2017:8:2256.

31. Casazza A, Laoui D, Wenes M, Rizzolio S, Bassani N, Mambretti M, et al. Impeding macrophage entry into hypoxic tumor areas by Sema3A/Nrp1 signaling blockade inhibits angiogenesis and restores antitumor immunity. Cancer Cell. 2013;24:695-709.

32. Palazon A, Goldrath AW, Nizet V, Johnson RS. HIF transcription factors, inflammation, and immunity. Immunity. 2014;41:518-28.

33. Barsoum IB, Koti M, Siemens DR, Graham CH. Mechanisms of hypoxiamediated immune escape in cancer. Cancer Res. 2014;74:7185-90.

34. Larkin J, Chiarion-Sileni V, Gonzalez R, Grob JJ, Cowey CL, Lao CD, et al. Combined Nivolumab and Ipilimumab or Monotherapy in Untreated Melanoma. N Engl J Med. 2015;373:23-34.

35. Reck M, Rodriguez-Abreu D, Robinson AG, Hui R, Csoszi T, Fulop A, et al Pembrolizumab versus Chemotherapy for PD-L1-Positive Non-Small-Cell Lung Cancer. N Engl J Med. 2016;375:1823-33.

36. Luo H, Tu G, Liu Z, Liu M. Cancer-associated fibroblasts: a multifaceted driver of breast cancer progression. Cancer Lett. 2015;361:155-63.

37. Luo Y, Zhou H, Krueger J, Kaplan C, Lee SH, Dolman C, et al. Targeting tumor-associated macrophages as a novel strategy against breast cancer. J Clin Invest. 2006;116:2132-41.

38. Ozdemir BC, Pentcheva-Hoang T, Carstens JL, Zheng X, Wu CC, Simpson TR, et al. Depletion of carcinoma-associated fibroblasts and fibrosis induces immunosuppression and accelerates pancreas cancer with reduced survival. Cancer Cell. 2014;25:719-34.

39. Zhu Y, Knolhoff BL, Meyer MA, Nywening TM, West BL, Luo J, et al. CSF1/ CSF1R blockade reprograms tumor-infiltrating macrophages and improves response to T-cell checkpoint immunotherapy in pancreatic cancer models. Cancer Res. 2014;74:5057-69.

40. Huang Y, Goel S, Duda DG, Fukumura D, Jain RK. Vascular normalization as an emerging strategy to enhance cancer immunotherapy. Cancer Res. 2013; 73:2943-8.

41. Giaccia AJ, Schipani E. Role of carcinoma-associated fibroblasts and hypoxia in tumor progression. Curr Top Microbiol Immunol. 2010;345:31-45.

42. Chaturvedi P, Gilkes DM, Takano N, Semenza GL. Hypoxia-inducible factordependent signaling between triple-negative breast cancer cells and mesenchymal stem cells promotes macrophage recruitment. Proc Natl Acad Sci U S A. 2014;111:E2120-9.

43. Lin J, Zhu Z, Xiao H, Wakefield MR, Ding VA, Bai Q, et al. The role of IL-7 in Immunity and Cancer. Anticancer Res. 2017;37:963-7.

44. Rutz S, Wang X, Ouyang W. The IL-20 subfamily of cytokines--from host defence to tissue homeostasis. Nat Rev Immunol. 2014;14:783-95.

45. Loskog A, Dzojic H, Vikman S, Ninalga C, Essand M, Korsgren O, et al. Adenovirus CD40 ligand gene therapy counteracts immune escape mechanisms in the tumor Microenvironment. J Immunol. 2004;172:7200-5.

46. Schoenberger SP, Toes RE, van der Voort El, Offringa R, Melief CJ. T-cell help for cytotoxic $T$ lymphocytes is mediated by CD40-CD40L interactions. Nature. 1998;393:480-3.

47. Cole KE, Strick CA, Paradis TJ, Ogborne KT, Loetscher M, Gladue RP, et al. Interferon-inducible T cell alpha chemoattractant (I-TAC): a novel non-ELR CXC chemokine with potent activity on activated T cells through selective high affinity binding to CXCR3. J Exp Med. 1998;187:2009-21.

48. Shurin GV, Ferris RL, Tourkova IL, Perez L, Lokshin A, Balkir L, et al. Loss of new chemokine CXCL14 in tumor tissue is associated with low infiltration by dendritic cells (DC), while restoration of human CXCL14 expression in tumor cells causes attraction of DC both in vitro and in vivo. J Immunol. 2005;174:5490-8.

49. Qiao G, Qin J, Kunda N, Calata JF, Mahmud DL, Gann P, et al. LIGHT Elevation Enhances Immune Eradication of Colon Cancer Metastases. Cancer Res. 2017;77:1880-91.

50. Noman MZ, Buart S, Van Pelt J, Richon C, Hasmim M, Leleu N, et al. The cooperative induction of hypoxia-inducible factor-1 alpha and STAT3 during hypoxia induced an impairment of tumor susceptibility to CTL-mediated cell lysis. J Immunol. 2009;182:3510-21.

51. Hasmim M, Noman MZ, Lauriol J, Benlalam H, Mallavialle A, Rosselli F, et al. Hypoxia-dependent inhibition of tumor cell susceptibility to CTL mediated lysis involves NANOG induction in target cells. J Immunol. 2011;187:4031-9.

52. Nakai $Y$, Isayama $H$, ljichi $H$, Sasaki $T$, Takahara $N$, Ito $Y$, et al. A multicenter phase II trial of gemcitabine and candesartan combination therapy in 
patients with advanced pancreatic cancer: GECA2. Invest New Drugs. 2013; 31:1294-9.

53. Mantovani A, Cassatella MA, Costantini C, Jaillon S. Neutrophils in the activation and regulation of innate and adaptive immunity. Nat Rev Immunol. 2011;11:519-31.

54. Ebner S, Hofer S, Nguyen VA, Furhapter C, Herold M, Fritsch P, et al. A novel role for IL-3: human monocytes cultured in the presence of IL-3 and IL-4 differentiate into dendritic cells that produce less IL-12 and shift Th cell responses toward a Th2 cytokine pattern. J Immunol. 2002;168:6199-207.

55. Ugel S, De Sanctis F, Mandruzzato S, Bronte V. Tumor-induced myeloid deviation: when myeloid-derived suppressor cells meet tumor-associated macrophages. J Clin Invest. 2015;125:3365-76.

56. Murray PJ, Allen JE, Biswas SK, Fisher EA, Gilroy DW, Goerdt S, et al. Macrophage activation and polarization: nomenclature and experimental guidelines. Immunity. 2014:41:14-20.

57. Mittal SK, Roche PA. Suppression of antigen presentation by IL-10. Curr Opin Immunol. 2015;34:22-7.

58. Akane K, Kojima S, Mak TW, Shiku H, Suzuki H. CD8+CD122+CD49dlow regulatory $T$ cells maintain $T$-cell homeostasis by killing activated $T$ cells via Fas/FasL-mediated cytotoxicity. Proc Natl Acad Sci U S A. 2016;113:2460-5.

59. Curiel TJ, Coukos G, Zou L, Alvarez X, Cheng P, Mottram P, et al. Specific recruitment of regulatory $T$ cells in ovarian carcinoma fosters immune privilege and predicts reduced survival. Nat Med. 2004;10:942-9.

60. Sharma P, Hu-Lieskovan S, Wargo JA, Ribas A. Primary, Adaptive, and Acquired Resistance to Cancer Immunotherapy. Cell. 2017;168:707-23.

61. Karin $\mathrm{N}$. The multiple faces of $\mathrm{XXCL12}$ (SDF-1alpha) in the regulation of immunity during health and disease. J Leukoc Biol. 2010;88:463-73.

62. Facciabene A, Peng X, Hagemann IS, Balint K, Barchetti A, Wang LP, et al. Tumour hypoxia promotes tolerance and angiogenesis via CCL28 and T(reg) cells. Nature. 2011;475:226-30.

63. Welte T, Kim IS, Tian L, Gao X, Wang H, Li J, et al. Oncogenic mTOR signalling recruits myeloid-derived suppressor cells to promote tumour initiation. Nat Cell Biol. 2016:18:632-44.

64. Gabrilovich D. Mechanisms and functional significance of tumour-induced dendritic-cell defects. Nat Rev Immunol. 2004:4:941-52.

65. Su S, Liu Q, Chen J, Chen J, Chen F, He C, et al. A positive feedback loop between mesenchymal-like cancer cells and macrophages is essential to breast cancer metastasis. Cancer Cell. 2014;25:605-20.

66. Mantovani A, Sica A, Sozzani S, Allavena P, Vecchi A, Locati M. The chemokine system in diverse forms of macrophage activation and polarization. Trends Immunol. 2004;25:677-86.

67. Zhou SL, Zhou ZJ, Hu ZQ, Huang XW, Wang Z, Chen EB, et al. TumorAssociated Neutrophils Recruit Macrophages and T-Regulatory Cells to Promote Progression of Hepatocellular Carcinoma and Resistance to Sorafenib. Gastroenterology. 2016;150:1646-58.

68. Maecker H, Varfolomeev E, Kischkel F, Lawrence D, LeBlanc H, Lee W, et al. TWEAK attenuates the transition from innate to adaptive immunity. Cell. 2005:123:931-44.

Ready to submit your research? Choose BMC and benefit from:

- fast, convenient online submission

- thorough peer review by experienced researchers in your field

- rapid publication on acceptance

- support for research data, including large and complex data types

- gold Open Access which fosters wider collaboration and increased citations

- maximum visibility for your research: over $100 \mathrm{M}$ website views per year

At $\mathrm{BMC}$, research is always in progress.

Learn more biomedcentral.com/submissions 